\title{
Effect of the $Y$ chromosome on plasma high-density lipoprotein-cholesterol levels in Y-chromosome-consomic mouse strains
}

\author{
Jun-ichi Suto $^{1 *}$ and Kunio Satou ${ }^{2}$
}

\begin{abstract}
Background: Plasma high-density lipoprotein (HDL)-cholesterol level is a clinically important quantitative phenotype that widely varies among inbred mouse strains. Several genes or loci associated with plasma HDL-cholesterol levels have been identified on autosomes and the $X$ chromosome. In contrast, genes or loci on the $Y$ chromosome have not attracted significant attention hitherto. Therefore, we investigated the effects of the $Y$ chromosome on plasma HDL-cholesterol levels in Y-chromosome-consomic (Y-consomic) mouse strains.
\end{abstract}

Findings: Plasma HDL-cholesterol level data from 16 Y-consomic strains demonstrated that the Y chromosome substitutions significantly altered plasma HDL-cholesterol levels, i.e., variations in the plasma HDL-cholesterol level could be partially explained by $Y$ chromosome genes. We obtained the following results from the genotype data on 30 single nucleotide polymorphisms (SNPs), including nonsynonymous and synonymous SNPs and 9 polymorphisms in Sry: (1) Variation in rs46947134 of Uty was significantly associated with plasma HDL-cholesterol levels. (2) A CAG repeat number polymorphism in Sry was significantly associated with plasma HDL-cholesterol levels. (3) Strains with a certain haplotype of the Mus musculus domesticus-type Y chromosome had significantly lower plasma HDL-cholesterol levels than strains with a certain haplotype of the M. m. musculus-type $Y$ chromosome.

Conclusions: The effect of the Y chromosome on plasma HDL-cholesterol levels was confirmed in the Y-consomic strains. We identified several variants associated with plasma HDL-cholesterol levels. Because the physiological significance of various Y-linked genes remains unclear, the results of this study will provide further insights into the functions of Y-linked genes in lipid metabolism.

Keywords: HDL-cholesterol, Sry, Uty, Y-chromosome-consomic mouse strains

\section{Findings}

\section{Background}

Plasma high-density lipoprotein (HDL)-cholesterol level is a clinically important quantitative phenotype that widely varies among inbred mouse strains [1]. Plasma HDLcholesterol levels are genetically determined to a great extent [2]. The genetic basis of plasma HDL-cholesterol levels have been explored by the means of quantitative trait locus (QTL) mapping, and numerous relevant QTLs have been identified on mouse chromosomes [2]. In addition, the analysis of a series of mouse mutants has provided direct evidence for the presence of plasma HDL-

\footnotetext{
* Correspondence: jsuto@affrc.go.jp

'Agrogenomics Research Center, National Institute of Agrobiological

Sciences, Tsukuba, Ibaraki 305-8634, Japan

Full list of author information is available at the end of the article
}

cholesterol genes (MGI, Mouse Genome Informatics; http://www.informatics.jax.org). Most of these genes or loci are autosomal or X-linked, and the Y chromosome has not attracted significant attention hitherto. However, the effect of the Y chromosome on cholesterol levels has been implicated in several human studies, although the findings have been rather controversial [3-9]. To address this controversy, we performed genetic analyses of plasma HDL-cholesterol levels in Y-chromosome-consomic (referred to as Y-consomic hereafter) strains, in which the $\mathrm{Y}$ chromosome from various inbred mouse strains had been introgressed onto an inbred DH/Sgn strain background $[10,11]$. We can eliminate the phenotypic effects of autosomes and the $\mathrm{X}$ chromosome using the Y-consomic strains. Because our results suggested that the Y chromosome had significant effects on plasma HDL-cholesterol 
levels, we also aimed to identify specific associations between plasma lipid level and Y-linked gene polymorphisms. The identification of Y-linked genes associated with plasma HDL-cholesterol levels will provide further insights into the functions of Y-linked genes in lipid metabolism and the inheritance of coronary artery diseases in men [9].

\section{Methods}

The inbred mouse strain DH/Sgn (referred to as $\mathrm{DH}$ hereafter) was maintained at the National Institute of Agrobiological Sciences (NIAS, Tsukuba, Japan). We had previously established the following Y-consomic strains: $\mathrm{DH}-\mathrm{Chr} \mathrm{Y}^{\mathrm{A}}(\mathrm{n}=8)$, DH-Chr $\mathrm{Y}^{\mathrm{AKR}}(\mathrm{n}=9)$, DH-Chr $\mathrm{Y}^{\mathrm{B} 6}$ $(\mathrm{n}=12)$, DH-Chr $\mathrm{Y}^{\mathrm{BALB}}(\mathrm{n}=9)$, DH-Chr $\mathrm{Y}^{\mathrm{C} 3 \mathrm{H}}(\mathrm{n}=12)$, DH-Chr $\mathrm{Y}^{\mathrm{CAST}}(\mathrm{n}=16)$, DH-Chr $\mathrm{Y}^{\mathrm{CBA}}(\mathrm{n}=11)$, DH-Chr $\mathrm{Y}^{\mathrm{CF} 1}(\mathrm{n}=8)$, DH-Chr $\mathrm{Y}^{\mathrm{DDD}}(\mathrm{n}=16)$, DH-Chr $\mathrm{Y}^{\mathrm{DH}}$ (identical to $\mathrm{DH}, \mathrm{n}=11)$, DH-Chr $\mathrm{Y}^{\mathrm{KK}}(\mathrm{n}=5), \mathrm{DH}-\mathrm{Chr} \mathrm{Y}^{\mathrm{RF}}$ $(\mathrm{n}=14)$, DH-Chr $\mathrm{Y}^{\mathrm{RR}}(\mathrm{n}=16)$, DH-Chr $\mathrm{Y}^{\mathrm{SIL}} \quad(\mathrm{n}=16)$, DH-Chr $Y^{S S}(n=10)$, and DH-Chr Y ${ }^{\text {SWR }}(n=9)$. These Y-consomic strains were also maintained at the NIAS. In total, 182 Y-consomic strain mice were used in this study.

All mice were maintained in a specific pathogen-free facility with a regular 12-h light:12-h dark light cycle, controlled temperature, and humidity. Food (CRF-1, Oriental Yeast Co. Ltd., Tokyo, Japan) and water were freely available throughout the experimental period. All animal procedures were approved by the Institutional Animal Care and Use Committee of NIAS, and the experiments were performed in accordance with the committeeapproved guidelines.

At 80 days of age, mice were killed with an overdose of ether after a 4-h fast. Blood was then drawn from the heart into microtubes with heparin as an anticoagulant. The tubes were centrifuged at 7,000 rpm for $5 \mathrm{~min}$ at $4{ }^{\circ} \mathrm{C}$ to separate plasma from whole blood. Plasma samples were maintained at $-70^{\circ} \mathrm{C}$ until use. Plasma HDLcholesterol levels were enzymatically determined using a spectrophotometer with clinical chemical kits (Test Wako, Wako Pure Chemical Industries Ltd., Osaka, Japan). Plasma HDL-cholesterol levels were determined in sample from which low-density lipoprotein and very low-density lipoprotein fractions had been previously precipitated with phosphotungstic acid and magnesium chloride.

Single nucleotide polymorphism (SNP) genotyping was performed by direct sequencing of the PCR product of the genomic region containing the SNP site. Thirty SNPs were identified in the $15 \mathrm{Y}$-consomic strains (DH-Chr $\mathrm{Y}^{\mathrm{DH}}$ was not genotyped). These SNP loci were selected on the basis of SNP data retrieved from the Mouse Phenome Database (MPD, http://phenome.jax.org). A high-density strain set comprising 18 inbred strains had 18 SNPs associated with nonsynonymous amino acid changes. Of them, rs51394161, which was located on exon 5 of Zfy2, could not be determined; therefore, 17 nonsynonymous SNPs were genotyped. The MPD search also yielded 25 synonymous SNPs, and of them, 13 were genotyped. In this study, the following SNPs were genotyped: rs47359684, rs47900677, rs46080695, rs52139814, rs45850354, rs480 64925, rs51995337, rs51133250, rs50647790, rs51277152, rs48685451, rs48834187, rs46947134, rs51756947, rs48 554025, rs47574660, rs51766109, rs49468864, rs49623242, rs51230091, rs49614307, rs48926479, rs51025923, rs48 512209, rs47293184, rs51685350, rs47616691, rs51560704, rs46643293, and rs51529727.

The nucleotide (nt) sequence of Sry was also determined by direct sequencing of the PCR product. Sry polymorphisms included nucleotide substitutions at seven sites and a number of major CAG repeats at two sites [12]. The following polymorphisms were genotyped: nt 8491, nt 8701, nt 8711, nt 8731, number of first CAG repeats starting at nt 8733 , number of second CAG repeats starting at nt 8811, nt 8930, nt 8934, and nt 9006. The nt numbers are based on the GenBank entry X67204.

Trait data distribution normality in Y-consomic mice was tested using the Shapiro-Wilk W test (JMP8, SAS Institute Japan Inc., Tokyo).

Y-linked genetic variations controlling plasma HDLcholesterol levels were identified using the following three-step approach [11]: (1) The effects of genes on autosomes and the $\mathrm{X}$ chromosome were eliminated by using Y-consomic strains, and the net phenotypic effects of Y-linked genes were assessed. (2) The Dunnett's multiple comparison test or Steel test, with the background $\mathrm{DH}$ strain as a reference, was used to determine if a trait was Y-linked. (3) The data from all strains were assembled on the basis of SNP genotypes and the statistical significance of differences was assessed. Two groups partitioned by genotype were compared using the Student's or Welch's $t$-test, and three groups were compared with one-way analysis of variance (ANOVA). On the basis of the number of SNP loci (n) genotyped, the significant threshold $P$ value was determined as $0.05 / \mathrm{n}$ with the Bonferroni correction test.

Statistical comparisons among the haplotype-based Y-consomic strain groups were performed with TukeyKramer honest significant difference (HSD) tests.

\section{Results and discussion}

Among the Y-consomic strains, the $\mathrm{DH}-\mathrm{Chr} \mathrm{Y}^{\mathrm{A}}, \mathrm{DH}-$ Chr $\mathrm{Y}^{\mathrm{B} 6}$, DH-Chr $\mathrm{Y}^{\mathrm{BALB}}$, DH-Chr $\mathrm{Y}^{\mathrm{C} 3 \mathrm{H}}, \mathrm{DH}-\mathrm{Chr} \mathrm{Y}^{\mathrm{CBA}}$, DH-Chr $\mathrm{Y}^{\mathrm{CF} 1}$, DH-Chr $\mathrm{Y}^{\mathrm{DH}}$, DH-Chr $\mathrm{Y}^{\mathrm{KK}}, \mathrm{DH}-\mathrm{Chr} \mathrm{Y}^{\mathrm{RR}}$, and DH-Chr $\mathrm{Y}^{\mathrm{SS}}$ strains possess the Mus musculus musculus-type $\mathrm{Y}$ chromosome $\left(\mathrm{Y}^{\mathrm{Mus}}\right)$, whereas the $\mathrm{DH}-\mathrm{Chr}$ $\mathrm{Y}^{\mathrm{AKR}}$, DH-Chr $\mathrm{Y}^{\mathrm{DDD}}$, DH-Chr $\mathrm{Y}^{\mathrm{RF}}$, DH-Chr $\mathrm{Y}^{\mathrm{SJL}}$, and $\mathrm{DH}-\mathrm{Chr} \mathrm{Y}^{\mathrm{SWR}}$ strains possess the M. m. domesticus-type $\mathrm{Y}$ chromosome $\left(\mathrm{Y}^{\mathrm{Dom}}\right)$. The strains, $\mathrm{Y}^{\mathrm{Mus}}$ vs. $\mathrm{Y}^{\text {Dom }}$, were 
Table 1 Plasma high-density lipoprotein (HDL)-cholesterol levels in Y-consomic strains

\begin{tabular}{llll}
\hline $\begin{array}{l}\text { Y chromosome } \\
\text { donor strain }\end{array}$ & $\begin{array}{l}\text { Plasma HDL-cholesterol } \\
\text { level }(\mathbf{m g} / \mathbf{d l}, \text { mean } \pm \text { SE) }\end{array}$ & P value vs. DH & $\begin{array}{l}\text { Sample } \\
\text { size }\end{array}$ \\
\hline DH & $102.4 \pm 2.1$ & 11 \\
A & $100.2 \pm 2.0$ & 0.9952 & 8 \\
C3H & $98.6 \pm 2.8$ & 0.9965 & 12 \\
SS & $97.2 \pm 4.1$ & 0.9999 & 10 \\
CBA & $96.2 \pm 2.5$ & 0.5958 & 11 \\
CAST & $94.7 \pm 3.3$ & 0.8287 & 16 \\
RR & $93.2 \pm 2.4$ & 0.0683 & 16 \\
RF & $93.0 \pm 2.3$ & 0.1198 & 14 \\
BALB & $89.5 \pm 3.4$ & 0.0790 & 9 \\
CF1 & $89.1 \pm 1.8$ & 0.0172 & 8 \\
DDD & $85.7 \pm 2.3$ & 0.0037 & 16 \\
B6 & $84.7 \pm 1.8$ & 0.0018 & 12 \\
SJL & $84.3 \pm 1.8$ & 0.0011 & 16 \\
AKR & $83.8 \pm 2.4$ & 0.0046 & 9 \\
SWR & $82.5 \pm 4.8$ & 0.0131 & 9 \\
KK & $76.7 \pm 3.5$ & 0.0254 & 5 \\
\hline
\end{tabular}

classified on the basis of the following criteria: (1) a Cto- $\mathrm{T}$ transitional substitution at nt 8491 in the high mobility group (HMG) box of Sry ( $\mathrm{Y}^{\mathrm{Mus}}$ had $\mathrm{T}$ and $\mathrm{Y}^{\text {Dom }}$ had C) [13] and (2) the presence of a C-to-T change that created a TAG termination codon at nt 9006 in the third major CAG repeat starting at nt 8985 in $\mathrm{Y}^{\text {Dom }}$ [14], which was absent in $\mathrm{Y}^{\mathrm{Mus}}$ (the mouse Sry gene has four major sites consisting approximately 10 CAG repeats). The partitioning of the strains into either $\mathrm{Y}^{\mathrm{Mus}}$ or $\mathrm{Y}^{\mathrm{Dom}}$ was compatible with the descriptions in the previous studies $[15,16]$.

Plasma HDL-cholesterol levels in 182 mice from 16 Yconsomic strains exhibited a bell-shaped distribution curve but did not strictly follow a normal distribution (data not shown). However, when the data from the DHChr $\mathrm{Y}^{\mathrm{DH}}$ strain was excluded (i.e., 171 mice from 15 strains), the plasma HDL-cholesterol level values followed a normal distribution. The DH-Chr $\mathrm{Y}^{\mathrm{DH}}$ strain was excluded because SNP/Sry genotyping was not performed in this strain, and it is not included in the subsequent statistical analyses.

The plasma HDL-cholesterol level was compared for each Y-consomic strain (Table 1). According to the Steel test results, the DH-Chr $\mathrm{Y}^{\mathrm{CF} 1}, \mathrm{DH}-\mathrm{Chr} \mathrm{Y}^{\mathrm{DDD}}$, DH-Chr $\mathrm{Y}^{\mathrm{B} 6}$, DH-Chr $\mathrm{Y}^{\mathrm{SJL}}$, DH-Chr $\mathrm{Y}^{\mathrm{AKR}}$, DH-Chr $\mathrm{Y}^{\mathrm{SWR}}$, and $\mathrm{DH}-\mathrm{Chr} \mathrm{Y}^{\mathrm{KK}}$ strains exhibited significantly lower plasma HDL-cholesterol levels than the DH-Chr $\mathrm{Y}^{\mathrm{DH}}$ strain. Therefore, the $\mathrm{Y}$ chromosome substitution had a significant influence on plasma HDL-cholesterol levels.

Table 2 shows the typical polymorphic patterns among 30 SNPs and 9 Sry polymorphisms identified in the 15 Y-consomic strains [11]. Most SNPs/polymorphisms could be classified as one of these patterns. These SNP loci were selected on the basis of SNP data retrieved from MPD. A high-density strain set, comprising 18 inbred strains, had 18 SNPs associated with nonsynonymous amino acid changes. Of them, rs51394161, which was located on exon 5 of $Z f y 2$, could not be determined; therefore, 17 nonsynonymous SNPs were genotyped. In addition, an MPD search yielded 25 synonymous SNPs, and of them, 13 were genotyped. Sry polymorphisms included nt substitutions at seven sites and a number of major CAG repeats at two sites [12].

Table 3 summarizes the results of the statistical analyses. Mice were divided into two or three groups according to the SNP or polymorphism in their Sry gene. Statistically significant differences in mean values between or among groups were then tested. On the basis of the Bonferroni correction test, the significance threshold at $\alpha=0.05$ level was 0.00128 because 39 polymorphisms were examined.

In the analysis of variation in the gene for the ubiquitously transcribed tetratricopeptide repeat gene, Y chromosome (Uty; rs46947134) was significantly associated with the plasma HDL-cholesterol level. Strains with a $\mathrm{C}$ allele had significantly lower plasma HDL-cholesterol levels than those with a $\mathrm{G}$ allele. rs46947134 was a nonsynonymous SNP and was accompanied by a His-to-Asp amino acid change, but the physiologic significance of this amino acid change remains unclear. In humans, Russo et al. [8] explored genetic variants and reported the absence of a polymorphism in UTY in three ethnic groups. Recently, Bloomer et al. [17]

Table 2 Patterns of rs46947134 and Sry polymorphism in Y-consomic strains

\begin{tabular}{|c|c|c|c|c|c|c|c|c|c|c|c|c|c|c|c|c|}
\hline Gene & SNP/polymorphism & A & B6 & BALB & $\mathrm{C} 3 \mathrm{H}$ & $\mathrm{CBA}$ & CF1 & KK & RR & SS & CAST & AKR & DDD & $\mathrm{RF}$ & SJL & SWR \\
\hline Uty & rs46947134 & C & C & C & G & G & C & C & G & C & C & C & C & C & C & C \\
\hline Sry & No. of CAG repeats starting at nt 8733 & 11 & 11 & 11 & 12 & 12 & 11 & 11 & 12 & 11 & 11 & 9 & 9 & 9 & 9 & 9 \\
\hline Sry & No. of CAG repeats starting at nt 8811 & 12 & 12 & 12 & 10 & 10 & 12 & 12 & 10 & 12 & 12 & 13 & 12 & 13 & 12 & 12 \\
\hline Sry & Nts at 8491 and 8711 & $\mathrm{~T}$ & $\mathrm{~T}$ & $\mathrm{~T}$ & $\mathrm{~T}$ & $\mathrm{~T}$ & $\mathrm{~T}$ & $\mathrm{~T}$ & $\mathrm{~T}$ & $\mathrm{~T}$ & C & C & C & C & C & C \\
\hline Usp9y & rs51766109 & C & C & C & $\mathrm{T}$ & $\mathrm{T}$ & C & C & $\mathrm{T}$ & C & $\mathrm{T}$ & $\mathrm{T}$ & $\mathrm{T}$ & $\mathrm{T}$ & $\mathrm{T}$ & $\mathrm{T}$ \\
\hline Usp9y & rs49468864 1$)$ & A & A & A & A & A & A & A & A & A & A & G & $\mathrm{G}$ & $\mathrm{G}$ & $\mathrm{G}$ & $\mathrm{G}$ \\
\hline
\end{tabular}

1) In addition to rs49468864 in Usp9y, many SNPs showed similar polymorphic pattern to rs49468864 [11]. 
Table 3 Effects of gene polymorphisms on plasma high-density lipoprotein (HDL)-cholesterol level in Y-consomic strains

\begin{tabular}{|c|c|c|c|c|c|}
\hline \multirow{2}{*}{$\frac{\text { SNP/Gene }}{\text { rs46947134 }}$} & \multirow[t]{2}{*}{ Polymorphism } & \multicolumn{3}{|c|}{ Plasma HDL-cholesterol level (mg/dl, mean \pm SE) } & \multirow[t]{2}{*}{$P$ value } \\
\hline & & C & G & & \\
\hline \multirow[t]{2}{*}{$(U t y)$} & & $(n=132)$ & $(n=39)$ & & \\
\hline & & $88.8 \pm 0.9$ & $95.7 \pm 1.5$ & & 0.00046 \\
\hline \multirow[t]{3}{*}{ Sry } & No. of CAG repeats starting at nt 8733 & 9 & 11 & 12 & \\
\hline & & $(n=64)$ & $(n=68)$ & $(n=39)$ & \\
\hline & & $86.2 \pm 1.2$ & $91.3 \pm 1.4$ & $95.7 \pm 1.5$ & $4.73 \times 10^{-5}$ \\
\hline \multirow[t]{3}{*}{ Sry } & No. of CAG repeats starting at nt 8811 & 10 & 12 & 13 & \\
\hline & & $(n=39)$ & $(n=109)$ & $(n=23)$ & \\
\hline & & $95.7 \pm 1.5$ & $88.7 \pm 1.1$ & $89.4 \pm 1.9$ & NS $(0.0021)^{2)}$ \\
\hline \multirow[t]{3}{*}{ Sry } & Nts at nt 8491 and 8711 & $\mathrm{~T}$ & C & & \\
\hline & & $(n=91)$ & $(n=80)$ & & \\
\hline & & $92.6 \pm 1.1$ & $87.9 \pm 1.2$ & & NS $(0.0050)$ \\
\hline rs51766109 & & C & $\mathrm{T}$ & & \\
\hline \multirow[t]{2}{*}{ (Usp9y) } & & $(n=52)$ & $(n=119)$ & & \\
\hline & & $90.2 \pm 1.5$ & $90.5 \pm 1.0$ & & NS (0.90) \\
\hline rs49468864 ${ }^{1)}$ & & A & G & & \\
\hline \multirow[t]{2}{*}{ (Usp9y) } & & $(n=107)$ & $(n=64)$ & & \\
\hline & & $92.9 \pm 1.1$ & $86.2 \pm 1.2$ & & $5.27 \times 10^{-5}$ \\
\hline
\end{tabular}

1) In addition to rs49468864 in Usp9y, many SNPs showed a similar polymorphic pattern to rs49468864 [11].

2) NS: not significant.

observed that an increased risk of coronary artery disease was associated with reduced $U T Y$ expression. However, it is unknown whether the $\mathrm{G} / \mathrm{C}$ variants in mouse Uty are associated with the expression level.

The number of first major CAG repeats, starting at nt 8733 of Sry, was significantly associated with plasma HDL-cholesterol levels. Strains with 9 CAG repeats had significantly lower plasma HDL-cholesterol levels than those with 11 or 12 repeats. Because Sry sequences, except those for HMG boxes, are poorly conserved among species, and Sry genes other than mouse do not possess a CAG-repeat stretch, it is impossible to directly apply the results from mouse studies to other mammalian species [18]. Nevertheless, Sry has been recently described to play roles other than testis determination [19]. An association between the Y chromosome and blood pressure has been repeatedly reported in rats and humans [3,20-24], and Sry is thought to be the most promising candidate for the $\mathrm{Y}$ chromosomal effect [23]. Because both hypertension and dyslipidemia are major components in determining cardiovascular risk, it is not surprising that Sry plays role in lipid metabolism. Overall, we found 22 polymorphic SNPs, as represented by rs49468864 in Usp9y, were significantly associated with plasma HDL-cholesterol levels.

On the basis of the six SNPs and Sry polymorphisms haplotypes (Table 2), Y-consomic strains were partitioned into five groups (Table 4). Tukey-Kramer HSD
Table 4 Plasma HDL-cholesterol level in Y-consomic strains partitioned by haplotypes based on Y-linked SNPs and Sry polymorphisms

\begin{tabular}{|c|c|c|c|}
\hline Group & Strains & Sample size & $\begin{array}{l}\text { Plasma HDL-cholesterol } \\
\text { level }(\mathrm{mg} / \mathrm{dl} \text {, mean } \pm \mathrm{SE})\end{array}$ \\
\hline \multirow[t]{3}{*}{1} & DDD & 41 & $84.4 \pm 1.6$ \\
\hline & SJL & & \\
\hline & SWR & & \\
\hline \multirow[t]{2}{*}{2} & AKR & 23 & $89.4 \pm 2.1$ \\
\hline & RF & & \\
\hline \multirow[t]{6}{*}{3} & A & 52 & $90.2 \pm 1.4$ \\
\hline & B6 & & \\
\hline & BALB & & \\
\hline & CF1 & & \\
\hline & KK & & \\
\hline & SS & & \\
\hline 4 & CAS & 16 & $94.7 \pm 2.6$ \\
\hline \multirow[t]{4}{*}{5} & $\mathrm{C} 3 \mathrm{H}$ & 39 & $95.7 \pm 1.6$ \\
\hline & CBA & & \\
\hline & DBA & & \\
\hline & RR & & \\
\hline
\end{tabular}


tests were used to compare plasma HDL-cholesterol levels among the five haplotype-based groups. A significant difference was observed between Groups 1 and 5 $(\mathrm{P}<0.0001)$. Group 1 consisted of strains with $\mathrm{Y}^{\mathrm{Dom}}$, whereas Group 5 consisted of strains with $\mathrm{Y}^{\mathrm{Mus}}$. Therefore, it was concluded that strains with a certain haplotype of $Y^{\text {Dom }}$ had significantly lower plasma HDL-cholesterol levels than strains with a certain haplotype of $\mathrm{Y}^{\mathrm{Mus}}$. However, it cannot be said that the differences in HDLcholesterol levels among the Y-consomic strains were neatly and tidily explained by partitioning based on Ylinked haplotypes.

The effect of the $\mathrm{Y}$ chromosome on plasma HDLcholesterol levels was confirmed in the Y-consomic strains. We identified several variants associated with plasma HDL-cholesterol levels. Because the physiological significance of various Y-linked genes remains unclear, the results of this study will provide further insights into the functions of Y-linked genes in lipid metabolism.

\section{Conclusion}

The effect of the Y chromosome on plasma HDLcholesterol levels was confirmed in Y-consomic mouse strains. We identified several genetic variants associated with plasma HDL-cholesterol levels. Because the physiological significance of many Y-linked genes remains unclear, the results of this study provide new insights into the functions of Y-linked genes in lipid metabolism.

\section{Competing interests}

The authors declare that they have no competing interests.

\section{Authors' contributions}

JS and KS conceived the study. JS conducted the experiments on mice. JS and KS performed data analyses. JS and KS wrote the manuscript. Both authors read and approved the final manuscript.

\section{Acknowledgment}

This work was supported by Grants-in-Aid for Scientific Research from the Japan Society for the Promotion of Science (Nos. 15500305 and 19500373).

\section{Author details}

${ }^{1}$ Agrogenomics Research Center, National Institute of Agrobiological Sciences, Tsukuba, Ibaraki 305-8634, Japan. ${ }^{2}$ Center for Animal Disease Control and Prevention, National Institute of Animal Health, Tsukuba, Ibaraki 305-0856, Japan.

Received: 8 January 2014 Accepted: 20 June 2014

Published: 25 June 2014

\section{References}

1. Suto J, Matsuura S, Yamanaka H, Sekikawa K: Quantitative trait loci that control plasma lipid concentrations in hereditary obese $\mathrm{KK}$ and $\mathrm{KK}-A^{y}$ mice. Biochim Biophys Acta 1999, 1453:385-395.

2. Wang $X$, Paigen B: Genetics of variation in HDL cholesterol in humans and mice. Circ Res 2005, 96:27-42.

3. Kren C, Qi N, Krenova D, Zidek V, Sladká M, Jáchymová M, Míková B, Horky K, Bonne A, Van Lith HA, Van Zutphen BF, Lau YF, Pravenec M, St Lezin E: $Y$-chromosome transfer induces changes in blood pressure and blood lipids in SHR. Hypertension 2001, 37:1147-1152.
4. Shoji M, Tsutaya S, Shimada J, Kojima K, Kasai T, Yasujima M: Lack of association between $\mathrm{Y}$ chromosome Alu insertion polymorphism and hypertension. Hypertens Res 2002, 25:1-3.

5. Charchar FJ, Tomaszewski M, Lacka B, Zakrzewski J, Zukowska-Szczechowska E, Grzeszczak W, Dominiczak AF: Association of the human Y chromosome with cholesterol levels in the general population. Arterioscler Thromb Vasc Biol 2004, 24:308-312.

6. Russo P, Venezia A, Lauria F, Strazzullo P, Cappuccio FP, lacoviello L, Barba G, Siani A: HindIII (+/-) polymorphism of the Y chromosome, blood pressure, and serum lipids: no evidence of association in three white populations. Am J Hypertens 2006, 19:331-338.

7. Hiura Y, Fukushima Y, Kokubo Y, Okamura T, Goto Y, Nonogi H, Takahashi R, Iwai N: Effects of the $Y$ chromosome on cardiovascular risk factors in Japanese men. Hypertens Res 2008, 31:1687-1694.

8. Russo P, Siani A, Miller MA, Karanam S, Esposito T, Gianfrancesco F, Barba G, Lauria F, Strazzullo P, Cappuccio FP: Genetic variants of Y chromosome are associated with a protective lipid profile in black men. Arterioscler Thromb Vasc Biol 2008, 28:1569-1574.

9. Charchar FJ, Bloomer LD, Barnes TA, Cowley MJ, Nelson CP, Wang Y, Denniff M, Debiec R, Christofidou P, Nankervis S, Dominiczak AF, Bani-Mustafa A, Balmforth AJ, Hall AS, Erdmann J, Cambien F, Deloukas P, Hengstenberg C, Packard C, Schunkert H, Ouwehand WH, Ford I, Goodall AH, Jobling MA, Samani NJ, Tomaszewski M: Inheritance of coronary artery disease in men: an analysis of the role of the $Y$ chromosome. Lancet 2012, 379:915-922.

10. Suto J: Genetic dissection of testis weight in a mouse strain having an extremely large testis: major testis weight determinants are autosomal rather than Y-linked on the basis of comprehensive analyses in Y-chromosome consomic strains. Proc Jpn Acad Ser B 2008, 84:393-406.

11. Suto J: Genetic dissection of testis weight in mice: quantitative trait locus analysis using F2 intercrosses between strains with extreme testis weight, and association study using Y-consomic strains. Mamm Genome 2011, 22:648-660.

12. Eicher EM: Sex and trinucleotide repeats. Nat Genet 1994, 6:221-223.

13. Kunieda T, Toyoda Y: Nucleotide sequence of mouse Sry gene is different between $Y$ chromosome originating from Mus musculus musculus and Mus musculus domesticus. Genomics 1992, 13:236-237.

14. Coward P, Nagai K, Chen D, Thomas HD, Nagamine CM, Lau YFC: Polymorphism of a CAG trinucleotide repeat within Sry correlates with B6.Y ${ }^{\text {Dom }}$ sex reversal. Nat Genet 1994, 6:245-250.

15. Bishop CE, Boursot P, Baron B, Bonhomme F, Hatat D: Most classical Mus musculus domesticus laboratory mouse strains carry a Mus musculus musculus Y chromosome. Nature 1985, 315:70-73.

16. Nishioka Y: Y-chromosomal DNA polymorphism in mouse inbred strains. Genet Res Camb 1987, 50:69-72.

17. Bloomer LD, Nelson CP, Eales J, Denniff M, Christofidou P, Debiec R, Moore J, Consortium C, Zukowska-Szczechowska E, Goodall AH, Thompson J, Samani NJ, Charchar FJ, Tomaszewski M: Male-specific region of the $Y$ chromosome and cardiovascular risk. Arteriorscler Thromb Vasc Biol 2013, 33:1722-1727

18. Graves JAM: The rise and fall of SRY. Trends Genet 2002, 18:259-264.

19. Turner ME, Ely D, Prokop J, Milsted A: Sry, more than testis determination? Am J Physiol Regul Integr Comp Physiol 2011, 301:R561-R571.

20. Ely $D L$, Turner ME: Hypertension in the spontaneously hypertensive rat is linked to the $Y$ chromosome. Hypertension 1990, 16:277-281.

21. Davidson AO, Schork N, Jaques BC, Kelman AW, Sutcliffe RG, Reid JL, Dominiczak AF: Blood pressure in genetically hypertensive rats. Influence of the $Y$ chromosome. Hypertension 1995, 26:452-459.

22. Ellis JA, Stebbing M, Harrap SB: Association of the human $Y$ chromosome with high blood pressure in the general population. Hypertension 2000, 36:731-733.

23. Ely D, Turner M, Milsted A: Review of the $Y$ chromosome and hypertension. Braz J Med Biol Res 2000, 33:679-691.

24. CharChar FJ, Tomaszewski M, Padmanabhan S, Lacka B, Upton MN, Inglis GC, Anderson NH, McConnachie A, Zukowska-Szczechowska E, Grzeszczak W, Connell JM, Watt GC, Dominiczak AF: The Y chromosome effect on blood pressure in two European populations. Hypertension 2002, 39:353-356.

doi:10.1186/1756-0500-7-393

Cite this article as: Suto and Satou: Effect of the $Y$ chromosome on plasma high-density lipoprotein-cholesterol levels in Y-chromosome-consomic mouse strains. BMC Research Notes 2014 7:393. 